\title{
Obstructive sleep apnea and Parkinson's disease: characteristics and associated factors
}

\author{
Apneia obstrutiva do sono e doença de Parkinson: características e fatores relacionados \\ Manoel Alves SOBREIRA-NETO1,2, Márcio Alexandre PENA-PEREIRA ${ }^{3}$,Emmanuelle Silva Tavares \\ SOBREIRA ${ }^{2,3}$, Marcos Hortes Nisihara $\mathrm{CHAGAS}^{4}$, Carlos Maurício Oliveira de ALMEIDA ${ }^{3}$, Regina Maria \\ França FERNANDES ${ }^{3}$, Vitor TUMAS ${ }^{3}$, Alan Luiz ECKELI ${ }^{3}$
}

\begin{abstract}
Obstructive sleep apnea (OSA) occurs in up to $66 \%$ of Parkinson's disease (PD) patients, higher than in the general population. Although it is more prevalent, the relationship between OSA and PD remains controversial, with some studies confirming and others denying the relationship of OSA with some risk factors and symptoms in patients with PD. Objective: To determine the factors associated with OSA in PD patients. Methods: A cross-sectional study was performed with 88 consecutive patients with PD from the outpatient clinic. Participants underwent clinical interviews with neurologists and a psychiatrist, assessment using standardized scales (Epworth Sleepiness Scale, Parkinson's Disease Questionnaire, Pittsburgh Sleep Quality Index and, for individuals with a diagnosis of restless legs syndrome/Willis-Ekbom disease, the International Restless Legs Syndrome Rating Scale), and video-polysomnography. Results: Individuals with PD and OSA were older and had less insomnia than those with PD without OSA. Regarding the polysomnographic variables, we observed a lower percentage of stage N3 sleep, a higher arousal index, and a higher oxygen desaturation index in those individuals with OSA, relative to those without OSA. In the multivariate analysis, only the percentage of stage N3 sleep and the oxygen desaturation index were significantly different. Besides this, most of the PD patients with OSA had a correlation with sleeping in the supine position (58\% of OSA individuals). Conclusion: The PD patients showed a high prevalence of OSA, with the supine position exerting a significant influence on the OSA in these patients, and some factors that are associated with OSA in the general population did not seem to have a greater impact on PD patients.
\end{abstract}

Keywords: Parkinson disease; sleep; sleep apnea, obstructive.

\section{RESUMO}

A Apneia Obstrutiva do Sono (AOS) chega a acometer até $66 \%$ dos pacientes com doença de Parkinson (DP), prevalência maior, portanto, que a da população geral. Embora seja mais prevalente, a relação entre AOS e DP permanence controversa, com trabalhos confirmando e outros afastando a relação de AOS com alguns fatores de risco e sintomas em pacientes com DP. Objetivo: Determinar quais fatores estão relacionados à AOS em pacientes com DP. Métodos: Estudo transversal, observacional, realizado com 88 pacientes com DP, provenientes do ambulatório de hospital público. Os pacientes foram submetidos à entrevista clínica com neurologista e psiquiatra, à aplicação de escalas padronizadas (escala de sonolência de Epworth, questionário de qualidade de vida da DP, índice de qualidade de sono de Pittsburgh e, para os indivíduos com diagnóstico de Síndrome das Pernas Inquietas, a escala internacional de graduação da SPI), e vídeo-polissonografia. Resultados: Indivíduos com DP e AOS apresentaram maior idade e menor prevalência de insônia crônica que os indivíduos com DP, sem AOS. Em relação às variáveis polissonográficas, observamos uma baixa proporção de sono N3, elevado índice de microdespertares e maior índice de desaturações nos indivíduos com AOS, em comparação ao grupo sem AOS. Na análise multivariada, apenas a porcentagem de sono N3 e o índice de dessaturação permaneceu significativo. Além disso, a maior parte dos pacientes tem relação com a posição supina (58\% dos pacientes com AOS). Conclusão: Pacientes com DP apresentaram prevalência elevada de AOS, a posição supina exerceu influência importante na AOS destes pacientes e alguns fatores que estão associados à AOS na população geral não mostraram impacto significativo nos pacientes com DP.

Palavras-chave: Doença de Parkinson; sono; apneia obstrutiva do sono

\footnotetext{
${ }^{1}$ Universidade Federal do Ceará, Faculdade de Medicina, Departamento de Clínica Médica, Fortaleza CE, Brasil;

¿Universidade Unichristus, Fortaleza CE, Brasil;

${ }^{3}$ Universidade de São Paulo, Faculdade de Medicina de Ribeirão Preto, Departamento de Neurosciências, Ribeirão Preto SP, Brasil;

«Universidade Federal de São Carlos, Departamento de Gerontologia, São Carlos SP, Brasil.

Manoel Alves Sobreira-Neto (iD) https://orcid.org/0000-0001-9619-6551
}

Correspondence: Manoel Alves Sobreira Neto; Faculdade de Medicina da UFCE; Rua Prof. Costa Mendes, 1408 / 4². Andar; $60430-140$ Fortaleza CE, Brasil; E-mail: manoelsobreira@yahoo.com.br

Conflict of interest: There is no conflict of interest to declare.

Received 25 February 2019; Received in final form 06 May 2019; Accepted 26 May 2019. 
Obstructive sleep apnea (OSA) is characterized by recurrent episodes of partial or total obstruction of the upper airways during sleep, frequently accompanied by sleep fragmentation ${ }^{1}$. The prevalence of OSA occurs in up to $66 \%$ of PD patients, and it is higher than in the general population ${ }^{2,3}$.

Three factors may explain the occurrence of this high prevalence $^{4,5}$. First, we know that the patency of the airway is regulated, among other factors, by dopaminergic neurons ${ }^{4}$ and that these are reduced in PD by the neurodegenerative process. Second, mouth breathing is a prevalent dysfunction in patients with $\mathrm{PD}$ in the later stages of the disease. This fact increases the chance of pharyngeal collapse ${ }^{5}$. Finally, alterations in motor coordination and autonomic dysfunction are observed in PD patients, possibly explaining the relationship between OSA and $\mathrm{PD}^{4}$.

Although it is more prevalent, the relationship between OSA and PD remains controversial, with some studies confirming and others refuting the relationship of OSA with some risk factors and symptoms in patients with $\mathrm{PD}^{6,7,8,9,10,11,12,13}$.

Contrary to what was expected, some studies demonstrated that the presence of OSA in patients with $\mathrm{PD}$ was not associated with excessive sleepiness, cognitive deficit, depressive symptoms, nocturia, or cerebrovascular diseases $^{6-9}$. Specific aspects of PD, such as the levodopa equivalent dose and disease severity, were also not related to $\mathrm{OSA}^{10}$. Moreover, risk factors involved in OSA in the general population, such as increased body mass index, males and older age, were not more prevalent in patients with OSA and PD ${ }^{10,11}$.

On the other hand, Chotinaiwattarakul et al. conducted a study with 228 individuals and observed the worse quality of life scores and higher prevalence of depression symptoms in patients with PD and a higher risk of $\mathrm{OSA}^{12}$. Mery et al. demonstrated an association of respiratory events during sleep between OSA and excessive sleepiness and cognition ${ }^{13}$. When assessing the outcome of OSA treatment in PD patients, Neikrug et al. documented an improvement in excessive sleepiness, measured subjectively and objectively, through the multiple sleep latency test ${ }^{14}$.

Therefore, the results of the relationship between OSA and PD are conflicting. Thus, the theme deserves to be reinvestigated, since OSA is known to be related to cognitive dysfunction and excessive sleepiness, which are striking features in PD patients.

\section{METHODS}

\section{Study design and population}

A cross-sectional study was performed on patients with PD from the tertiary outpatient clinic of movement disorders of the Hospital das Clínicas, Faculty of Medicine of Ribeirão Preto - University of São Paulo, São Paulo, Brazil, over a period of 21 months.
In total, 124 consecutive individuals with PD were approached on the day of their usual consultation. Ninety of these individuals provided informed consent, and two of them did not complete the research protocol. Subsequently, the patients who agreed to participate underwent a clinical assessment with neurologists specialized in sleep medicine and movement disorders, and with a psychiatrist. The patients also underwent polysomnography with a maximum interval of two weeks after the initial assessment. During this time, there was no change in drug treatment.

This study was approved by the Ethics Committee of the Hospital das Clínicas, Faculty of Medicine of Ribeirão Preto - University of São Paulo, under protocol number 13410, following the ethical principles of the Declaration of Helsinki.

\section{Clinical evaluation}

Clinical evaluation was performed using standardized scales, and assessment of sleep disorders, cognitive framework, motor and psychiatric symptoms of PD.

The scales related to the quality of life and sleep used were the Epworth Sleepiness Scale ${ }^{15,16}$, Parkinson's Disease Questionnaire $^{17}$, Pittsburgh Sleep Quality Index ${ }^{18}$ and, for individuals diagnosed with restless legs syndrome/WillisEkbom disease, the International Restless Legs Syndrome Rating Scale ${ }^{16,19,20}$.

To detect and to diagnose sleep disorders according to the International Classification of Sleep Disorders - third edition, a clinical evaluation was performed by a neurologist specialized in sleep medicine ${ }^{21}$. The PD patients with OSA were classified as positional OSA according to Mador et al. ${ }^{22}$ criteria. Supine-predominant OSA was defined by a nonsupine apnea-hypopnea index (AHI) equal to or more than five per hour, with a more than $50 \%$ reduction in the nonsupine AHI when compared with the supine AHI. Supineinduced OSA was defined by a nonsupine AHI less than five per hour with a more than $50 \%$ reduction in the nonsupine AHI when compared with the supine AHI. Non-positional OSA was classified when neither of the two criteria above were met, and for patients who had not slept 15 minutes or more in both positions (supine and nonsupine), whom we could not classify ${ }^{22}$.

The assessment of functional impairment was performed by a neurologist specialized in movement disorders. The following scales were used: the Unified Parkinson's Disease Rating Scale ${ }^{23}$, Hoehn and Yahr Scale for staging Parkinson's disease, and the Schwab and England Activities of Daily Living Scale. For the cognitive assessment, the Mini-Mental State Examination and Global Deterioration Scale were used $^{24}$. For motor and cognitive evaluation, patients were evaluated during the best "on" period possible.

To achieve a psychiatric diagnosis following the criteria of the Diagnostic and Statistical Manual of Mental Disorders, Fourth Edition, of the American Psychiatric Association (DSM-IV), a structured clinical interview for 
Axis I mental disorders of the DSM-IV was used, translated and adapted for Portuguese ${ }^{25}$.

\section{Polysomnography}

Polysomnography was performed with a digital polygraph (computerized sleep system; Biologic Sleepscan Vision EEG, Natus Bio-logic Systems Inc., San Carlos, CA). Data were collected using an electroencephalogram (according to the International 10-20 System: Fp1-M1, Fp2-M2, F3-M1, F4-M2, C3-M1, C4-M2, P3-M1, P4-M2, F7-M1, F8-M2, T3-M1, T4-M2, T5-M1, T6-M2, O1-M1, $\mathrm{O} 2-\mathrm{M} 2, \mathrm{Fz}-\mathrm{Cz}, \mathrm{Cz}-\mathrm{Pz}$ ), bilateral electrooculogram (E1-M2, E2-M1), electrocardiogram (modified V2 lead), and surface electromyography of the mental and submental muscles. Surface electrodes were placed on both anterior tibialis muscles, masseters, and extensors of the fingers. Digital video was recorded with an infrared camera (Sony Ipela., CA) and then synchronized with the polysomnography data. Respiration was monitored as follows: airflow was measured by a nasal pressure transducer system (AcSleep 119, Biolink Medical, São Paulo, Brazil) and nasal and mouth thermocouple airflow sensor (Pro-Tech Services Inc., Mukilteo, WA); chest and abdominal efforts were measured by respiratory inductive plethysmographic belts (Pro-Tech zRIP module, Pro-Tech Services Inc.); arterial $\mathrm{SaO}_{2}$ was measured by pulse oximetry (Netlink Headbox, Natus Bio-logic Systems Inc.); snoring sounds were measured using a snoring microphone; body position was determined using a sensor (Netlink Body Sensor Position, Natus Bio-logic Systems Inc.). The scoring of sleep stages and all of the technical parameters applied were performed using the AASM Manual for the Scoring of Sleep and Associated Events: Rules, Terminology, and Technical Specification $(2007)^{26}$.

\section{Statistical analysis}

The Kolmogorov-Smirnov test was used to determine the type of distribution of the variables. For variables with a normal distribution, parametric tests such as Student's t-test or analysis of variance were used. Variables without a normal distribution were evaluated using the nonparametric MannWhitney or Kruskal-Wallis test. Pearson's coefficient was used in the correlation analysis of numeric variables with a normal distribution, and Spearman's correlation coefficient was used for the analysis of numerical variables without normal distribution. The hypothesis tests were conducted to verify the nullity of the correlation coefficients. In the analysis of categorical variables in two or more groups, the chisquare test or Fisher's exact test were used, according to the expected frequency in cells. Linear regression analysis was used to calculate the predictive coefficients, for dependent quantitative variables. For the multiple correlation analysis, logistic regression analysis was used for binary categorical dependent variables. The software packages Microsoft
Office Excel, IBM SPSS Statistics 19, and R 3.1.0 were used to construct and analyze the database.

\section{RESULTS}

Of the 88 participants, $55(62.5 \%)$ were diagnosed with OSA. Of these patients, 25 had mild OSA, 22 had moderate OSA, and eight had severe OSA. Among the individuals with OSA, all 55 individuals complained of snoring, 33 patients reported episodes of suffocation during sleep, and 17 reported apnea during sleep.

Individuals with PD and OSA were older than those with PD without OSA (Table 1). Contrary to what was expected, no significant differences were observed between the groups with and without OSA, in the proportion of males, body mass index values, and scores on the Epworth Sleepiness Scale (Table 1).

Regarding the polysomnographic variables, we observed a lower percentage of non-rapid eye movement (NREM) stage N3 sleep, a higher arousal index, and a higher desaturation index in the individuals with OSA, in comparison with those without OSA (Table 2). On the other hand, the proportion of rapid eye movement sleep was similar for both groups (Table 2).

For the logistic regression analysis, we chose the presence of OSA as the dependent variable. We included as independent variables those with $\mathrm{p}<0.1$ that were not directly related to the OSA definition, such as age, micro-arousal index, the percentage of stage $\mathrm{N} 1$ sleep, the percentage of stage N3 sleep, the presence of insomnia, the presence of depression, excessive sweating, the oxygen desaturation index, and minimal $\mathrm{O}_{2}$ saturation value. After an initial analysis with the independent variables mentioned above, those with higher $\mathrm{p}$-values were progressively withdrawn until only those with $\mathrm{p}<0.05$ remained. Thus, the percentage of stage N3 sleep (estimated coefficient $=-0.06, p=0.04$ ), and oxygen desaturation index (estimated coefficient $=0.21, \mathrm{p}=0.02$ ) were significant in the final model.

\section{OSA classification according to position and related factors}

Most of the PD patients with OSA had a correlation with the supine position (58\% of OSA individuals). Of these patients with positional OSA, 22 individuals had a supineisolated OSA, and ten had supine-predominant OSA (Figure). Only seven patients had a non-positional OSA. We could not classify 16 OSA individuals because they did not sleep for 15 minutes in the supine and non-supine positions (Figure).

Analyzing the related factors with positional OSA, we found that supine-isolated OSA had a smaller number of apnea and hypopnea events than the other groups and, consequently, a lower oxygen desaturation index compared with others (Table 3). 
Table 1. Comparison of clinical and socio-demographic variables between the groups of PD patients with and without OSA ( $n=88)$.

\begin{tabular}{|c|c|c|c|}
\hline Variables & $P D+O S A(n=55)$ & $P D-O S A(n=33)$ & $\mathrm{p}$-value \\
\hline Age (years), mean \pm SD & $63 \pm 12$ & $57 \pm 10$ & 0.005 \\
\hline Sex (\% males) & 67.3 & 54.5 & 0.26 \\
\hline Schooling (years), mean \pm SD & $6 \pm 5$ & $6 \pm 4$ & 0.53 \\
\hline PD onset time (months), mean \pm SD & $103 \pm 66$ & $100 \pm 56$ & 0.93 \\
\hline Levodopa equivalent dose (mg), mean \pm SD & $798 \pm 424$ & $912 \pm 474$ & 0.3 \\
\hline Body mass index, mean $\pm \mathrm{SD}$ & $25 \pm 5$ & $25 \pm 4$ & 0.31 \\
\hline Epworth Sleepiness Scale, mean \pm SD & $12 \pm 6$ & $10 \pm 6$ & 0.36 \\
\hline Pittsburgh Sleep Quality Index, mean \pm SD & $9 \pm 4$ & $10 \pm 4$ & 0.92 \\
\hline Parkinson's Disease Questionnaire-39, mean \pm SD & $43.7 \pm 19.6$ & $44.0 \pm 16.4$ & 0.78 \\
\hline Unified Parkinson Disease Rating Scale - part III, mean \pm SD & $19 \pm 13$ & $18 \pm 11$ & 0.92 \\
\hline Global Deterioration Scale, mean \pm SD & $2 \pm 1$ & $2 \pm 1$ & 0.36 \\
\hline Mini-Mental State Examination scale, mean \pm SD & $24.5 \pm 4.2$ & $24.0 \pm 4.0$ & 0.42 \\
\hline Hoehn and Yahr, mean \pm SD & $2 \pm 0.3$ & $2 \pm 0.5$ & 0.90 \\
\hline Schwab and England, mean \pm SD & $83 \pm 16$ & $84 \pm 15$ & 0.96 \\
\hline Presence of REM sleep behavior disorder (\%) & 63.6 & 72.7 & 0.73 \\
\hline Presence of insomnia (\%) & 47.3 & 69.3 & 0.04 \\
\hline Presence of restless legs syndrome (\%) & 29.1 & 27.3 & 1.0 \\
\hline Presence of excessive fragmentary myoclonus (\%) & 65.5 & 51.5 & 0.26 \\
\hline Presence of bruxism (\%) & 3.7 & 12.5 & 0.08 \\
\hline Presence of alternate leg movement activation and/or hypnagogic foot tremor (\%) & 12.7 & 12.1 & 1.0 \\
\hline Presence of depression (\%) & 21.8 & 39.4 & 0.09 \\
\hline Presence of psychotic disorder (\%) & 16.4 & 9.1 & 0.52 \\
\hline Presence of anxiety disorder (\%) & 20 & 9.1 & 0.23 \\
\hline Presence of hypersalivation (\%) & 5.6 & 6.1 & 1.0 \\
\hline Presence of dysphagia (\%) & 0 & 1.9 & 1.0 \\
\hline Presence of dyskinesia (\%) & 37.0 & 45.5 & 0.5 \\
\hline Presence of nocturia (\%) & 58.2 & 54.5 & 0.82 \\
\hline Presence of anosmia (\%) & 20.4 & 21.2 & 1.0 \\
\hline Presence of excessive sweating (\%) & 22.2 & 39.4 & 0.09 \\
\hline Presence of constipation (\%) & 44.4 & 39.4 & 0.66 \\
\hline Use of benzodiazepine (\%) & 16.4 & 21.2 & 0.58 \\
\hline Use of antidepressant (\%) & 29.1 & 45.5 & 0.16 \\
\hline
\end{tabular}

PD: Parkinson's disease; OSA: obstructive sleep apnea; SD: standard deviation.

Table 2. Comparison of polysomnographic variables among the groups of PD patients with and without OSA $(n=88)$.

\begin{tabular}{|c|c|c|c|}
\hline Variables & $P D+O S A(n=55)$ & $P D-O S A(n=33)$ & $p$-value \\
\hline Total sleep time (hours), mean \pm SD & $5.0 \pm 1.4$ & $4.9 \pm 1.5$ & 0.86 \\
\hline Sleep efficiency $(\%)$, mean \pm SD & $66.5 \pm 17.7$ & $67.6 \pm 22.1$ & 0.87 \\
\hline Wake after sleep onset (min), mean \pm SD & $128.3 \pm 74.9$ & $133.4 \pm 77.4$ & 0.67 \\
\hline Wake after final arousal (min), mean \pm SD & $12.9 \pm 22.9$ & $10.2 \pm 13.9$ & 0.53 \\
\hline Sleep onset latency (min), mean \pm SD & $28.1 \pm 45.1$ & $25.0 \pm 29.0$ & 0.76 \\
\hline Sleep latency for REM sleep, mean \pm SD & $161.2 \pm 111.8$ & $154.7 \pm 108.5$ & 0.89 \\
\hline N1 sleep (\% total sleep time), mean \pm SD & $20.2 \pm 10.5$ & $16.9 \pm 11.3$ & 0.06 \\
\hline N2 sleep (\% total sleep time), mean \pm SD & $49.3 \pm 14.3$ & $46.3 \pm 10.6$ & 0.19 \\
\hline N3 sleep (\% total sleep time), mean \pm SD & $18.6 \pm 13.3$ & $27.2 \pm 11.5$ & 0.003 \\
\hline REM sleep (\% total sleep time), mean \pm SD & $11.9 \pm 9.4$ & $9.6 \pm 8.2$ & 0.31 \\
\hline Arousal index (events/hour), mean \pm SD & $27.3 \pm 12.0$ & $21.4 \pm 10.3$ & 0.03 \\
\hline Respiratory disturbance index (events/hour), mean \pm SD & $19.9 \pm 13.6$ & $2.2 \pm 1.3$ & 0.000 \\
\hline Apnea-hypopnea index in NREM sleep (events/hour), mean \pm SD & $19.2 \pm 14.8$ & $1.4 \pm 1.1$ & 0.000 \\
\hline Apnea-hypopnea index in NREM sleep (events/hour), mean \pm SD & $19.6 \pm 21.0$ & $2.9 \pm 3.7$ & 0.000 \\
\hline Apnea-hypopnea index in supine position (events/ hour), mean \pm SD & $30.6 \pm 24.6$ & $4.7 \pm 9.9$ & 0.001 \\
\hline Apnea-hypopnea index in nonsupine position (events/hour), mean \pm SD & $8.8 \pm 12.4$ & $0.57 \pm 0.88$ & 0.001 \\
\hline Oxygen desaturation index (events/hour) & $10.1 \pm 9.7$ & $1.5 \pm 6.2$ & 0.01 \\
\hline Periodic limb movements index (events/ h), mean \pm SD & $8.3 \pm 20.9$ & $20.3 \pm 55.2$ & 0.84 \\
\hline Position changes index (number/hour), mean \pm SD & $1.9 \pm 2.4$ & $2.1 \pm 2.7$ & 0.48 \\
\hline Time in the supine position (\%), mean \pm SD & $60.7 \pm 37$ & $52.3 \pm 35.6$ & 0.32 \\
\hline
\end{tabular}

OSA: obstructive sleep apnea; PD: Parkinson's disease; SD: standard deviation; NREM: non-rapid eye movement. 


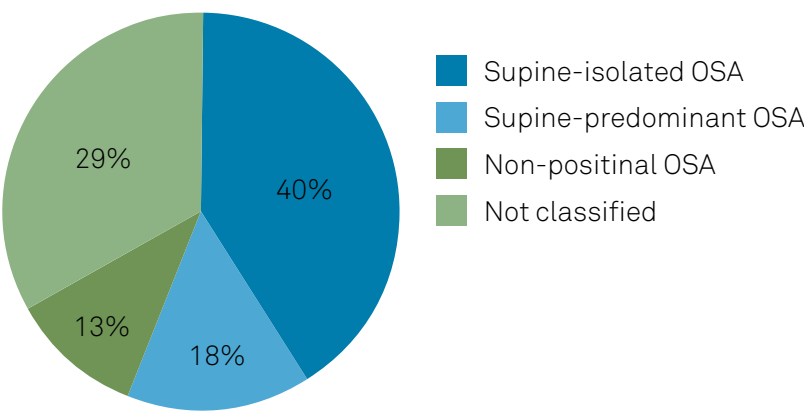

Figure. Classification of Parkinson's disease patients according to positional obstructive sleep apnea (OSA).

\section{DISCUSSION}

Parkinson's disease is the second most common degenerative disease ${ }^{27}$. Recently, many of its nonmotor manifestations, such as sleep disorders, including OSA, have received great attention ${ }^{12,13,14}$. Our study, with more than 80 patients with Parkinson's disease, represents the largest Brazilian study so far, that has tried to resolve the doubts between these conditions.

After univariate analysis, there was an association of the presence of OSA with older age, a lower rate of chronic

Table 3. Comparison of clinical and polysomnographic variables between the groups of PD patients according to positional OSA $(n=39)$.

\begin{tabular}{|c|c|c|c|c|}
\hline Variables & SIOSA $(n=22)$ & SPOSA $(n=10)$ & NPOSA $(n=7)$ & $\mathrm{p}$-value \\
\hline Age (years), mean \pm SD & $67.3 \pm 8.5$ & $63.5 \pm 13$ & $56 \pm 14.8$ & 0.18 \\
\hline Sex (\% males) & 63.6 & 81.8 & 83.3 & 0.43 \\
\hline PD onset time (months), mean \pm SD & $94.3 \pm 61.6$ & $105.3 \pm 65.7$ & $63 \pm 36.7$ & 0.38 \\
\hline Levodopa equivalent dose (mg), mean \pm SD & $728.3 \pm 436.8$ & $906.8 \pm 475.5$ & $812.5 \pm 384.6$ & 0.55 \\
\hline Body mass index, mean \pm SD & $42 \pm 16.1$ & $44.1 \pm 12$ & $45.9 \pm 28.7$ & 0.9 \\
\hline Epworth Sleepiness Scale, mean \pm SD & $11.4 \pm 6.5$ & $13.7 \pm 5.1$ & $9.6 \pm 3.9$ & 0.37 \\
\hline Pittsburgh Sleep Quality Index, mean \pm SD & $9.8 \pm 3.7$ & $10.7 \pm 4.6$ & $8.8 \pm 3.2$ & 0.63 \\
\hline Parkinson's Disease Questionnaire-39, mean \pm SD & $24.5 \pm 3.3$ & $24.5 \pm 5.7$ & $23.5 \pm 4.3$ & 0.66 \\
\hline Unified Parkinson Disease Rating Scale - part III, mean \pm SD & $18.4 \pm 10.1$ & $17.5 \pm 11.4$ & $12.3 \pm 7.7$ & 0.45 \\
\hline Hoehn and Yahr, mean \pm SD & $2 \pm 0.5$ & $1.9 \pm 0.4$ & $1.8 \pm 0.2$ & 0.63 \\
\hline Schwab and England, mean \pm SD & $86.3 \pm 12.5$ & $83.6 \pm 10.2$ & $90 \pm 12.6$ & 0.57 \\
\hline Presence of REM sleep behavior disorder (\%) & 78.9 & 66.7 & 80 & 0.75 \\
\hline Presence of insomnia (\%) & 50 & 54.5 & 66.7 & 0.76 \\
\hline Presence of restless legs syndrome (\%) & 31.8 & 27.3 & 33.3 & 0.95 \\
\hline Presence of depression (\%) & 22.7 & 36.4 & 16.7 & 0.60 \\
\hline Presence of psychotic disorder (\%) & 9.1 & 9.1 & 33.3 & 0.26 \\
\hline Presence of anxiety disorder (\%) & 27.3 & 18.2 & 16.7 & 0.77 \\
\hline Presence of hypersalivation (\%) & 0 & 9 & 16.6 & 0.68 \\
\hline Presence of dysphagia (\%) & 4.5 & 0 & 0 & 0.67 \\
\hline Presence of dyskinesia (\%) & 31.8 & 45.5 & 33.3 & 0.73 \\
\hline Presence of nocturia (\%) & 54.5 & 54.5 & 66.7 & 0.85 \\
\hline Presence of anosmia (\%) & 27.3 & 18.2 & 33.3 & 0.76 \\
\hline Presence of excessive sweating (\%) & 22.7 & 27.3 & 33.3 & 0.86 \\
\hline Presence of constipation (\%) & 54.5 & 36.4 & 16.7 & 0.21 \\
\hline Total sleep time $(h)$, mean \pm SD & $5.1 \pm 1.4$ & $4.3 \pm 1.6$ & $5.4 \pm 1.3$ & 0.23 \\
\hline Sleep efficiency (\%), mean \pm SD & $69.1 \pm 17.6$ & $21.1 \pm 6.4$ & $70.4 \pm 16.7$ & 0.35 \\
\hline Wake after sleep onset; (min), mean \pm SD & $117.4 \pm 51.3$ & $165.7 \pm 95.5$ & $142.5 \pm 91.6$ & 0.2 \\
\hline Wake after final arousal (min), mean \pm SD & $3.6 \pm 7.4$ & $16.7 \pm 19.4$ & $1.9 \pm 1.3^{\star}$ & 0.03 \\
\hline Sleep onset latency $(\min )$, mean \pm SD & $27.4 \pm 57.5$ & $18.2 \pm 19.9$ & $24 \pm 28.4$ & 0.86 \\
\hline Sleep latency for REM sleep, mean \pm SD & $195.8 \pm 124$ & $142.6 \pm 126.1$ & $138.1 \pm 44.6$ & 0.41 \\
\hline N1 sleep (\% total sleep time), mean \pm SD & $20.3 \pm 7.7$ & $35.3 \pm 15.7$ & $22.5 \pm 8.1$ & 0.64 \\
\hline N2 sleep (\%total sleep time), mean \pm SD & $48.1 \pm 15.1$ & $47.1 \pm 15$ & $47.4 \pm 9$ & 0.98 \\
\hline N3 sleep (\%total sleep time), mean \pm SD & $35.7 \pm 71$ & $13.5 \pm 14.2$ & $18.5 \pm 10.2$ & 0.51 \\
\hline Rapid eye movement sleep (\% total sleep time), mean \pm SD & $15.7 \pm 28$ & $15.2 \pm 14.4$ & $11.4 \pm 6.4$ & 0.91 \\
\hline Arousal index (events/ h), mean \pm SD & $25.1 \pm 7.7$ & $35.4 \pm 15.7$ & $32.6 \pm 18.6$ & 0.07 \\
\hline Respiratory disturbance index (events/hour), mean \pm SD & $16.9 \pm 7.9 *$ & $28.9 \pm 13$ & $25.4 \pm 24.7$ & 0.04 \\
\hline Apnea-hypopnea index in NREM sleep (events/hour), mean \pm SD & $14.2 \pm 8.1^{*}$ & $30.8 \pm 15.4$ & $29 \pm 22.4$ & 0.03 \\
\hline Apnea-hypopnea index in REM sleep (events/hour), mean \pm SD & $16.7 \pm 19.5$ & $21.1 \pm 15$ & $26.3 \pm 37$ & 0.65 \\
\hline Periodic limb movements index (events/hour), mean \pm SD & $5.3 \pm 16.7$ & $4.4 \pm 7.7$ & $15.4 \pm 34$ & 0.45 \\
\hline Oxygen desaturation index (events/hour), mean \pm SD & $7.4 \pm 5.1 *$ & $16.9 \pm 12.5$ & $10.1 \pm 13.2$ & 0.02 \\
\hline Position changes index (number/hour), mean \pm SD & $2.0 \pm 2.3$ & $3.6 \pm 3.1$ & $2.8 \pm 1.1$ & 0.22 \\
\hline Time in the supine position (\%), mean \pm SD & $65.8 \pm 28.6$ & $57.6 \pm 33.7$ & $43.5 \pm 31.9$ & 0.27 \\
\hline
\end{tabular}

PD: Parkinson's disease; OSA: obstructive sleep apnea; SIOSA: Supine-isolated OSA; SPOSA: Supine-predominant OSA; NPOSA: Non-positional OSA; SD: standard deviation. 
insomnia, shorter time of N3 sleep, a higher rate of arousal, and a higher oxygen desaturation index. In the multivariate analysis between patients with PD with and without OSA, we found a lower rate of N3 sleep and a higher oxygen desaturation index. This relationship was possibly not maintained in the multivariate analysis due to the small sample of patients evaluated.

An older age had already been documented as a risk factor for OSA in the general population ${ }^{11,28}$. As far as we know, there is no study that has documented the relationship of this variable with OSA in PD individuals.

The lower rate of insomnia observed in individuals with PD and OSA compared with those without OSA could be explained by a lower perception of sleep onset latency in OSA patients, due to the greater sleep deprivation in OSA patients caused by excessive fragmentation of sleep.

The higher number of arousals, as well as the shorter relative stage N3 sleep time observed in patients with OSA and PD in comparison with patients with PD without OSA, probably results from the excessive sleep fragmentation and the occurrence of obstructive respiratory events in sleep or the advanced age of this group.

The higher oxygen desaturation index may be explained by the repetitive interruption of respiration and consequent drops in oxygen saturation with subsequent improvement. Chronic intermittent hypoxia is one of the known causes of cardiovascular and cerebrovascular disease and could indicate a possible consequence of OSA in PD patients ${ }^{29}$.

The absence of a relationship between OSA and body mass index in the PD population is in accordance with the literature ${ }^{6,10,12,30}$. A different situation occurs in studies on OSA in the general population, in which it is clearly associated with obesity ${ }^{11,28,31}$. This fact demonstrates that, in the PD population, OSA appears to be more associated with factors such as motor incoordination, autonomic dysfunction and the presence of mouth breathing, than with weight ${ }^{4}$.

It is noteworthy that the studies that have assessed OSA in $\mathrm{PD}^{6,8,10,30}$, including ours, had a small number of patients, consisting of few individuals with moderate and severe OSA, possibly making it difficult to differentiate between groups with and without OSA. Also, most of the studies were not longitudinal, hampering more conclusive analyses. The few studies that followed the patients after treatment showed improvements in OSA repercussions in PD patients, such as cognition and excessive sleepiness ${ }^{32,33}$.

Apart from this, other possible explanations for the absence of a significant difference between the PD patients with and without OSA, with respect to known repercussions such as cognition and excessive sleepiness, are the instruments used to evaluate cognition and the difficulty of these patients in perceiving excessive sleepiness. The Mini-Mental State Examination may be insufficient to detect cognitive dysfunction in PD patients with OSA and could explain why we did not find differences between the cognition of OSA and
non-OSA patients. It might have been better to have used Addenbrooke's Cognitive Examination or Montreal Cognitive Assessment scales to evaluate $\operatorname{cognition}^{34}$. With regard to excessive sleepiness, Merino-Andreu et al. documented the inadequate perception of the wake-sleep transition in PD patients, and this could be a possible explanation for the absence of a difference in this variable, when measured by a subjective scale, such as the Epworth Sleepiness Scale ${ }^{35}$.

Many repercussions commonly associated with OSA, such as cardiovascular complications, nocturia, and depressive symptoms were not associated with OSA in PD. It has been claimed, for example, that cardiac denervation may protect PD patients with sleep apnea from cardiovascular diseases, or the difficulty of performing specialized evaluations and following a large number of individuals with PD demonstrates the need for new studies with better methodologies and with a larger number of individuals.

The sleep position, contrary to the way of other risk factors for OSA, seems to play a relevant role in PD patients ${ }^{36}$. We found that most of the PD patients with OSA had a correlation with the supine position, but the number of position changes during sleep and percentage of sleep time spent supine were not significant between the subgroups. In the PD population, the collapsibility of upper airways caused by a supine position during sleep could be explained by multiple neuromediator dysfunctions, including basal ganglia dopaminergic activity, leading to akinesia and incoordination associated with peripheral neuropathy and pharyngeal muscle atrophy ${ }^{37}$. These various factors facilitate the gravity effect on pharyngeal muscles, occluding the upper airway during sleep.

The supine-isolated OSA patients were classified in this way because they resolved a large part of the respiratory events by remaining in the non-supine position. They may have had this response because they had a lower rate of respiratory events, as found in results.

The present study had some limitations, such as the following: 1) it was carried out in a high-complexity outpatient hospital, therefore including patients with greater disease severity and duration, which restricts the generalization of our data; 2) there was a small number of patients, making it difficult to evaluate symptoms whose causes, in this population, are multifactorial, such as cognitive deficit and somnolence; 3 ) the absence of a control group without PD reduced the possibility of comparisons; 4) and the crosssectional design of the study made it difficult to establish cause-and-effect associations.

In conclusion, our study suggests that OSA is a common disease in PD patients, that the related factors are different from the general population, and that a supine position during sleep exerts a greater influence on respiratory sleep events in PD patients. Considering these results, we emphasize that new studies with a larger number of individuals, with longitudinal and post-treatment evaluation, could better evaluate the impact of OSA in the PD population. 


\section{References}

1. American Academy of Sleep Medicine. International Classification of Sleep Disorders. 3rd ed. Westchester: American Academy of Sleep Medicine; 2013.

2. Sobreira-Neto MA, Pena-Pereira MA, Sobreira ES, Chagas MH, Fernandes RM, Tumas V, et al. High frequency of sleep disorders in Parkinson's disease and its relationship with quality of life. Eur Neurol. 2017;78(5-6):330-7. https://doi.org/10.1159/000481939

3. Schulte EC, Winkelmann J. When Parkinson's disease patients go to sleep: specific sleep disturbances related to Parkinson's disease.J Neurol. 2011 May;258(S2 Suppl 2):S328-35. https://doi.org/10.1007/s00415-011-5933-0

4. Silva-Júnior FP, Prado GF, Barbosa ER, Tufik S, Togeiro SM. Sleep disordered breathing in Parkinson's disease: a critical appraisal. Sleep Med Rev. 2014 Apr;18(2):173-8. https://doi.org/10.1016/j.smrv.2013.04.005

5. Högl B. Sleep apnea in Parkinson's disease: when is it significant? Sleep Med. 2010 Mar;11(3):233-5. https://doi.org/10.1016/j.sleep.2009.11.008

6. Trotti LM, Bliwise DL. No increased risk of obstructive sleep apnea in Parkinson's disease. Mov Disord. 2010 Oct;25(13):2246-9. https://doi.org/10.1002/mds.23231

7. Sobreira-Neto MA, Pena-Pereira MA, Sobreira ES, Chagas MH, Almeida CM, Fernandes $\mathrm{RM}$, et al. Factors related to excessive sleepiness in patients with Parkinson's disease. Neurol Res. 2019 Mar;41(3):227-33. https://doi.org/10.1080/01616412.2018.1548746

8. De Cock VC, Abouda M, Leu S, Oudiette D, Roze E, Vidailhet M, et al. Is obstructive sleep apnea a problem in Parkinson's disease? Sleep Med. 2010 Mar;11(3):247-52. https://doi.org/10.1016/j.sleep.2009.05.008

9. Sobreira ES, Sobreira-Neto MA, Pena-Pereira MA, Chagas MH, Fernandes RM, Eckeli AL, et al. Global cognitive performance is associated with sleep efficiency measured by polysomnography in patients with Parkinson's disease. Psychiatry Clin Neurosci. 2019 May;73(5):248-53. https://doi.org/10.1111/pcn.12819

10. Nomura T, Inoue $Y$, Kobayashi M, Namba K, Nakashima K. Characteristics of obstructive sleep apnea in patients with Parkinson's disease. J Neurol Sci. 2013 Apr;327(1-2):22-4. https://doi.org/10.1016/j.jns.2013.01.036

11. Tufik S, Santos-Silva R, Taddei JA, Bittencourt LR. Obstructive sleep apnea syndrome in the Sao Paulo Epidemiologic Sleep Study. Sleep Med. 2010 May;11(5):441-6. https://doi.org/10.1016/j.sleep.2009.10.005

12. Chotinaiwattarakul W, Dayalu P, Chervin RD, Albin RL. Risk of sleep-disordered breathing in Parkinson's disease. Sleep Breath.2011 Sep;15(3):471-8. https://doi.org/10.1007/s11325-010-0362-3

13. Mery VP, Gros P, Lafontaine AL, Robinson A, Benedetti A, Kimoff RJ, et al. Reduced cognitive function in patients with Parkinson disease and obstructive sleep apnea. Neurology. 2017 Mar;88(12):1120-8. https://doi.org/10.1212/WNL.0000000000003738

14. Neikrug AB, Liu L, Avanzino JA, Maglione JE, Natarajan L, Bradley L, et al. Continuous positive airway pressure improves sleep and daytime sleepiness in patients with Parkinson disease and sleep apnea. Sleep (Basel). 2014 Jan;37(1):177-85. https://doi.org/10.5665/sleep.3332

15. Johns MW. A new method for measuring daytime sleepiness: the Epworth sleepiness scale. Sleep. 1991 Dec;14(6):540-5. https://doi.org/10.1093/sleep/14.6.540

16. Bertolazi F, Fagondes SC, Hoff LS, Pedro PV, Menna Barreto SS, John MW. Portuguese-language version of the Epworth sleepiness scale: validation for use in Brazil. J Bras Pneumol. 2009;35(9): 877-83. https://doi.org/10.1590/S1806-37132009000900009

17. Jenkinson C, Fitzpatrick R, Peto V, Greenhall R, Hyman N. The Parkinson's Disease Questionnaire (PDQ-39): development and validation of a Parkinson's disease summary index score. Age Ageing. 1997 Sep;26(5):353-7. https://doi.org/10.1093/ageing/26.5.353

18. Bertolazi A, Fagondes S, Perin C, Schonwald S, John A, De Barba $\mathrm{M}$, et al. Validation of the Pittsburgh sleep quality index in the brazilian portuguese language. Sleep. 2008;31(A):347.

19. Masuko AH, Carvalho LB, Machado MA, Morais JF, Prado LB, Prado GF. Translation and validation into the Brazilian Portuguese of the restless legs syndrome rating scale of the International Restless Legs Syndrome Study Group. Arq Neuropsiquiatr. 2008 Dec;66(4):832-6. https://doi.org/10.1590/S0004-282X2008000600011

20. Backhaus J, Junghanns K, Broocks A, Riemann D, Hohagen F. Test-retest reliability and validity of the Pittsburgh Sleep Quality Index in primary insomnia.J Psychosom Res. 2002 Sep;53(3):737-40 https://doi.org/10.1016/S0022-3999(02)00330-6

21. International Classification of Sleep Disorders. 2nd ed. Westchester (Illinois): American Academy of Sleep Medicine; 2005. DUPLICATA DA 1. Resposta: A referencia 1 diz respeito a $3^{a}$. edição e esta à $2^{\mathrm{a}}$. edição.

22. Mador MJ, Kufel TJ, Magalang UJ, Rajesh SK, Watwe V, Grant BJ. Prevalence of positional sleep apnea in patients undergoing polysomnography. Chest. 2005 Oct;128(4):2130-7. https://doi.org/10.1378/chest.128.4.2130

23. Martínez-Martín P, Gil-Nagel A, Gracia LM, Gómez JB, Martínez-Sarriés J, Bermejo F. Unified Parkinson's disease rating scale characteristics and structure. Mov Disord. 1994 Jan;9(1):76-83. https://doi.org/10.1002/mds.870090112

24. Bertolucci PH, Okamoto IH, Brucki SM, Siviero MO, Toniolo Neto J, Ramos LR. Applicability of the CERAD neuropsychological battery to Brazilian elderly. Arq Neuropsiquiatr. 2001 Sep;59 3-A:532-6. https://doi.org/10.1590/S0004-282X2001000400009

25. Del-Ben C, Vilela J, Crippa J, Hallak J, Labate C, Zuardi A. [Test-retest reliability of the structured clinical interview for DSM-IV - Clinical version (SCID-CV) translated into Portuguese]. Rev Bras Psiquiatr. 2001;23:156-9. Portuguese. https://doi.org/10.1590/S1516-44462001000300008

26. Iber C, Ancoli-Israel S, Chesson AL, Quan SF. The AASM Manual for scoring of sleep and associated events. Westchester: American Academy of Sleep Medicine; 2007.

27. Lau LM, Breteler MM. Epidemiology of Parkinson's disease. Lancet Neurol. 2006 Jun;5(6):525-35. https://doi.org/10.1016/S1474-4422(06)70471-9

28. Young T, Shahar E, Nieto FJ, Redline S, Newman AB, Gottlieb DJ, et al. Predictors of sleep-disordered breathing in community-dwelling adults: the Sleep Heart Health Study. Arch Intern Med. 2002 Apr;162(8):893-900. https://doi.org/10.1001/archinte.162.8.893

29. Beaudin AE, Waltz X, Hanly PJ, Poulin MJ. Impact of obstructive sleep apnoea and intermittent hypoxia on cardiovascular and cerebrovascular regulation. Exp Physiol. 2017 Jul;102(7):743-63. https://doi.org/10.1113/EP086051

30. Diederich NJ, Vaillant M, Leischen M, Mancuso G, Golinval S, Nati $\mathrm{R}$, et al. Sleep apnea syndrome in Parkinson's disease: a case-control study in 49 patients. Mov Disord. 2005 Nov;20(11):1413-8. https://doi.org/10.1002/mds.20624

31. Lindberg E, Gislason T. Epidemiology of sleep-related obstructive breathing. Sleep Med Rev. 2000 Oct;4(5):411-33. https://doi.org/10.1053/smrv.2000.0118

32. Kaminska M, Mery VP, Lafontaine AL, Robinson A, Benedetti A, Gros $\mathrm{P}$, et al. Change in cognition and other non-motor symptoms with 
obstructive sleep apnea treatment in Parkinson disease. J Clin Sleep Med. 2018 May;14(5):819-28. https://doi.org/10.5664/jcsm.7114

33. Harmell AL, Neikrug AB, Palmer BW, Avanzino JA, Liu L, Maglione JE, et al. Obstructive Sleep Apnea and Cognition in Parkinson's disease. Sleep Med. 2016 May;21:28-34. https://doi.org/10.1016/j.sleep.2016.01.001

34. Sobreira E, Pena-Pereira MA, Eckeli AL, Sobreira-Neto MA, Chagas MH, Foss MP, et al. Screening of cognitive impairment in patients with Parkinson's disease:

diagnostic validity of the Brazilian versions of the Montreal cognitive assessment and the Addenbrooke's cognitive examination-revised. Arq Neuropsiquiatr. 2015 Nov;73(11):929-33. https://doi.org/10.1590/0004-282X20150156
35. Merino-Andreu M, Arnulf I, Konofal E, Derenne JP, Agid Y.

Unawareness of naps in Parkinson's disease and in disorders with excessive daytime sleepiness. Neurology. 2003 May;60(9):1553-4. https://doi.org/10.1212/01.WNL.0000058905.71369.97

36. Cochen De Cock V, Benard-Serre N,

Driss V, Granier M, Charif M, Carlander

B, et al. Supine sleep and obstructive sleep apnea syndrome in Parkinson's disease. Sleep Med. 2015 Dec;16(12):1497-501. https://doi.org/10.1016/j.sleep.2014.09.014

37. Mu L, Sobotka S, Chen J, Su H, Sanders I, Adler $\mathrm{CH}$, et al. Altered pharyngeal muscles in Parkinson disease. J Neuropathol Exp Neurol. 2012 Jun;71(6):520-30. https://doi.org/10.1097/NEN.0b013e318258381b 